\title{
Complete response to ethnylestradiol prolonged for almost two years in patients with castration-resistant prostate cancer
}

\author{
Hiroshi Hongo, MD; Takeo Kosaka, MD, PhD; Mototsugu Oya, MD, PhD \\ Keio University School of Medicine, Shinjuku-ku, Tokyo, Japan
}

Cite as: Can Urol Assoc J 2014;8(11-12):e921-3. http://dx.doi.org/10.5489/cuaj.2293 Published online December 15, 2014.

\section{Abstract}

An 80-year-old man with an elevated prostate-specific antigen (PSA) level of $120 \mathrm{ng} / \mathrm{mL}$ ) presented to the hospital in February 2011. A prostate needle biopsy was performed, and pathological examination revealed prostatic adenocarcinoma. The Gleason score was $4+5=9$. Computed tomography revealed metastases of the pelvic lymph nodes. Combined androgen blockade was started. The PSA concentration decreased to $1.68 \mathrm{ng} / \mathrm{mL}$, but started increasing again in August 2012 to $6.08 \mathrm{ng} / \mathrm{mL}$. Although bicalutamide was discontinued due to antiandrogen withdrawal syndrome, the PSA concentration increased even more. The PSA concentration reached $21.62 \mathrm{ng} / \mathrm{mL}$ in September 2012, at which time ethnylestradiol was started. The PSA concentration decreased again and has remained below the limit of sensitivity for almost 2 years. To our knowledge, this is first case report describing a complete response to ethnylestradiol that lasted for almost 2 years in a patient with castration-resistant prostate cancer.

\section{Introduction}

Prostate cancer is the most prevalent cancer in American men. ${ }^{1}$ Metastatic prostate cancer is primarily treated by testicular androgen ablation (medical or surgical). Nonsteroidal antiandrogens and luteinizing hormone-releasing hormone (LHRH) analogues are mostly used for metastatic prostate cancer. Estrogens were used as palliative treatment for advanced prostate cancer in the 1980s, ${ }^{2}$ but their efficacy was limited.

Estrogens are sometimes used for castration-resistant prostate cancer (CRPC). ${ }^{3}$ However, the duration of the response to estrogens is limited to several months. We report a patient with metastatic prostate cancer who had complete remission for almost 2 years after administration of ethnylestradiol.

\section{Case report}

An 80-year-old man visited a nearby hospital in February 2011 for further evaluation of serum prostate-specific antigen (PSA) elevation that had reached $120 \mathrm{ng} / \mathrm{mL}$. Prostate needle biopsy was performed, and pathological examination showed prostatic adenocarcinoma and the Gleason score of $4+5=9$. Magnetic resonance imaging (MRI) showed a localized prostatic tumour. Computed tomography $(\mathrm{CT})$ revealed metastasis of the pelvic lymph nodes. Bone scintigraphy showed no metastases. Combined androgen blockade with leuprorelin and bicalutamide was started. The serum PSA level had decreased to $1.61 \mathrm{ng} / \mathrm{mL}$ the next month, but then gradually increased again to $6.08 \mathrm{ng} / \mathrm{mL}$ in August 2012 . Although bicalutamide was discontinued due to watching antiandrogen withdrawal syndrome, the serum PSA level increased even more. The serum PSA level reached $21.62 \mathrm{ng} / \mathrm{mL}$ in September 2012. The next month, the patient was diagnosed with CRPC. He visited our hospital for treatment. His PSA level was $27.03 \mathrm{ng} / \mathrm{mL}$, though the CT scan and bone scintigraphy showed no assessable metastases. We started ethnylestradiol (0.5 mg, twice a day) and low-dose aspirin (100 mg, once a day) to prevent the thrombotic complications of ethnylestradiol. The PSA level started declining again and dropped below the sensitivity limit in April 2013. The PSA nadir has remained stable until this present date about 2 years later. The PSA concentrations declined after the administration of ethnylestradiol. The PSA concentration was sustained under $0.01 \mathrm{ng} / \mathrm{mL}$ and the alkaline phosphatase concentration was within the normal range for almost 2 years.

The patient has had no adverse effect and has maintained good general health. 


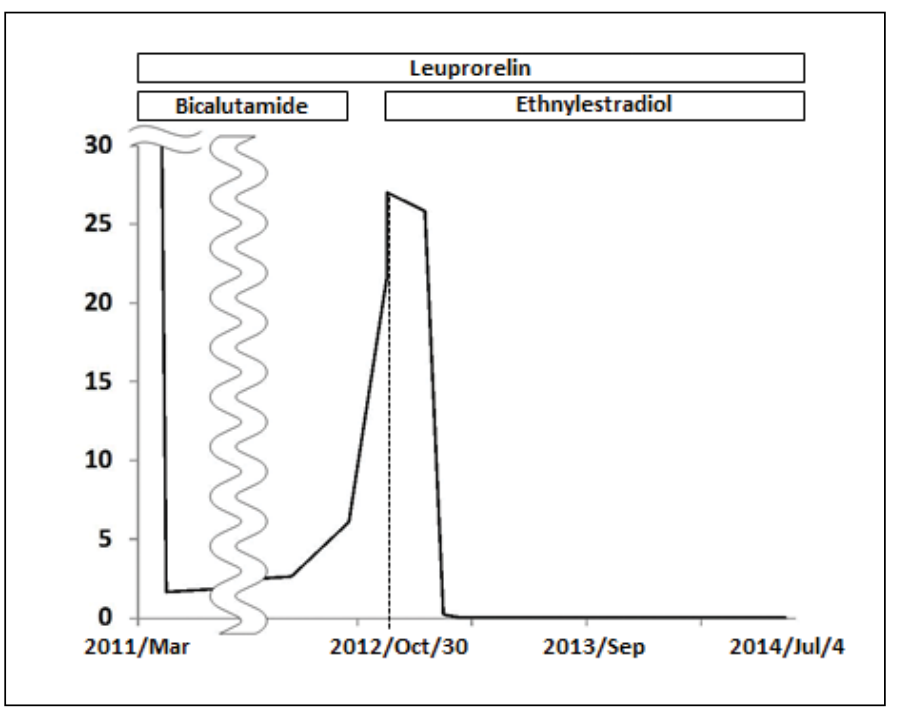

Fig. 1. Clinical course and changes in prostate-specific antigen concentration.

\section{Discussion}

Generally, prostate cancer responds well to first-line hormonal therapy even when it develops metastatic lesions. However, prostatic cancer ultimately becomes resistant to hormonal therapy.

Estrogens have been known to have therapeutic effects on prostatic cancer since the $1940 s .{ }^{4}$ Currently, estrogens are not first-line because they are known to cause severe cardiovascular complications. Estrogens were used mostly for CRPC. The response rate and progression-free survival (PFS) of ethnylestradiol were $70 \%$ and 200 days, respectively. ${ }^{5}$ It was also reported that PFS for high-risk prostate cancer was extremely short (0 to 4 months). Our patient had a high PSA level $(120 \mathrm{ng} / \mathrm{mL})$, so he was classified as high risk. The PSA level dropped after ethnylestradiol and has remained below the limit of sensitivity until the present date - almost 2 years later. There have been no reports of complete remission of PSA level (i.e., below $0.01 \mathrm{ng} / \mathrm{mL}$ ) for more than a year after starting estrogens in high-risk prostatic cancer patients developing CRPC.

It remains uncertain whether responders of estrogens have a better prognosis. Estrogens were not included in therapeutic options for CRPC in the 2013 American Urological Association Guidelines ${ }^{6}$ and the 2014 European Association of Urology guidelines. ${ }^{7}$ The efficacy of estrogens may be diminished by the complications of deep venous thrombosis (DVT) and myocardial infarction. ${ }^{8}$ Generally, the risk factors for DVT include active cancer and treatment of the cancer, a bedridden state, and obesity. ${ }^{9}$ Classical risk factors for cardiovascular disease are hyperlipidemia, smoking, diabetes, hypertension, and obesity. ${ }^{9}$ Estrogens may be particularly harmful for patients who have these risk factors.
In 2010 Izumi and colleagues found that the response rate ( $>50 \%$ PSA decline) for ethnylestradiol in Japanese CRPC patients was $69.6 \%$ and they observed no serious thrombotic events. The efficacy for CRPC and the effects on the cardiovascular system of ethnylestradiol may be different between races. In addition, we used low-dose aspirin to prevent thrombotic complications. These factors may have contributed to the long-term complete remission of our case without any adverse effects.

In recent years the tumour suppressive effect of estrogen receptors for prostate cancer has started to attract attention. ${ }^{10}$ Estrogens for CRPC may have a significant role beyond decreasing testosterone levels. Until recently, the only therapy available for metastatic CRPC was docetaxelprednisolone therapy, which often has strong adverse effects. Our patient has maintained an excellent physical condition for almost 2 years without such side effects. Estrogens clearly contributed to his improved quality of life. These findings suggest that estrogens may be administered in patients with CRPC who do not seem to tolerate chemotherapy and have few risk factors for DVT and cardiovascular disease, in conjunction with antiplatelet administration.

\section{Conclusion}

We have described a patient whose PSA level remained below the limit of sensitivity for almost 2 years with ethnylestradiol therapy. This therapy may be effective for CRPC patients who are at low risk of DVT and cardiovascular events.

Competing interests: Authors declare no competing financial or personal interests.

This paper has been peer-reviewed.

\section{References}

1. American Cancer Society. Cancer Facts and Figures 2014. Atlanta, GA; 2014. http://www.cancer. org/acs/groups/content/@research/documents/webcontent/acspc-042151.pdf. Accessed December 10, 2014.

2. Langeveld JW, Lycklama a Nijeholt AA, Jonas U. Oestrogen in the treatment of prostatic carcinoma. What is the safe and effective dose of ethinyloestradiol? Br J Urol 1989;63:76-9. http://dx.doi. org/10.1111/i.1464-410X.1989.tb05128.x

3. Izumi K, Kadono Y, Shima T, et al. Ethinylestradiol improves prostate-specific antigen levels in pretreated castration-resistant prostate cancer patients. Anticancer Res 2010;30:5201-5.

4. Fergusson JD. Carcinoma of prostate treated with oestrogens. Lancet 1946;2:551-6. http://dx.doi. org/10.1016/50140-6736(46)91014-8

5. Minato A, Fujimoto N, Kubo T, et al. Efficacy of estramustine phosphate according to risk classification of castration-resistant prostate cancer. Med Oncol 2012;29:2895-900. http://dx.doi.org/10.1007/ sl2032-012-0178-z

6. Cookson MS, Roth BJ, Dahm P, et al. Castration-resistant prostate cancer: AUA Guideline. J Urol 2013;190:429-38. http://dx.doi.org/10.1016/i.juro.2013.05.005 
Complete response to ethnylestradiol

7. Heidenreich A, Bastian PJ, Bellmunt J, et al. EAU guidelines on prostate cancer. Part II: Treatment of advanced, relapsing, and castration-resistant prostate cancer. Eur Urol 2014;65:467-79. http://dx.doi. org/10.1016/i.eururo.2013.11.002

8. Perry $C M$, McTavish D. Estramustine phosphate sodium. A review of its pharmacodynamic and pharmacokinetic properties, and therapeutic efficacy in prostate cancer. Drugs Aging 1995;7:49-74. http:// dx.doi.org/10.2165/00002512-199507010-00006

9. Previtali E, Bucciarelli P, Passamonti SM, et al. Risk factors for venous and arterial thrombosis. Blood Transfus 2011;9:120-38
10. Dey $P$, Jonsson $P$, Hartman J, et al. Estrogen receptors betal and beta 2 have opposing roles in regulating proliferation and bone metastasis genes in the prostate cancer cell line PC3. Mol Endocrinol 2012;26:19912003. http://dx.doi.org/10.1210/me.2012.1227

Correspondence: Dr. Takeo Kosaka, Department of Urology, Keio University School of Medicine, 35 Shinanomachi, Shinjuku-ku, Tokyo, 160-8582, Japan; takemduro@gmail.com 